\title{
REFUGIADOS E O DIREITO AO TRABALHO NO BRASIL: ANÁLISE SOB A ÓTICA DA LEGISLAÇÃO INTERNACIONAL E DAS OBRAS DE HANNAH ARENDT
}

Andrey Araujo de Araujo ${ }^{1}$ Fabiano De Aragão Veiga ${ }^{2}$

Resumo: É relevante tratar-se sobre o acolhimento e a integração dos refugiados no Brasil. Analisar-se-á a efetivação do acesso dos refugiados ao mercado de trabalho brasileiro, no século XXI, a partir da pesquisa sobre a legislação internacional e nas obras de Hannah Arendt. Nesta pesquisa qualitativa, aliada a procedimento bibliográfico, identificou-se omissão ou cortina de exclusão social deste grupo e a atualidade das ideias de Arendt. Conclui-se o inefetivo acesso ao emprego e a necessidade de políticas públicas mais incisivas. Tais fatos levam à exclusão social, com danos psicológicos e sociais, e à transgressão à identidade e à dignidade dos refugiados.

Palavras-Chave: Direitos Humanos. Direito Internacional. Integração. Mercado de Trabalho. Refugiados.

\section{REFUGEES AND THE RIGHT TO WORK IN BRAZIL: ANALYSIS FROM THE PERSPECTIVE OF INTERNATIONAL LEGISLATION AND THE WORKS OF HANNAH ARENDT}

\begin{abstract}
It is relevant to treat to reception and integration of refugees in Brazil. This paper analyze the effective acess of refugees to the Brazilian labor market atually, beased on research on international law and the works of Hannah Arendt. In this qualitative research, combined with a bibliographic procedure, the omission of curtain of social exclusion of this group and the relevance of Arendt's ideas were identified. It concludes the ineffective acess to employment and the need for more incisive public policies. These facts lead to exclusion, with psychological and social damage, and transgression to the identity and dignity of refugees.
\end{abstract}

Keywords: Human rights. International rights. Integration. Labor market. Refugees.

\section{INTRODUÇÃO}

A comunidade internacional passou a ter grande preocupação com os refugiados após a Segunda Guerra Mundial. Este momento histórico fez com que se iniciasse um grande fluxo migratório por conta dos judeus, que abandonaram a Alemanha, e dos nacionais de diversos

\footnotetext{
1 * Mestrando em Constitucionalização do Direito na Universidade Federal de Sergipe. Especialista em Direito Processual (PUC-MG). Advogado; andrey_araujo@hotmail.com.; CEP: 49009140.

2 *Juiz do Trabalho. Mestrando em Constitucionalização do Direito na Universidade Federal de Sergipe. Especialista em Direito Constitucional. Especialista em Direito e Processo do Trabalho. fabiano.trt05@gmail.com.; CEP: 41.820.420.
} 
países, que deixaram seus lugares de origem, fugindo dos horrores da guerra e do nazismo. No contexto atual, tem-se nova e intensa preocupação com os mesmos grupos. Isso porque vivencia-se uma das mais intensas crises migratórias, impulsionada por conflitos armados, crises humanitárias, políticas e sociais em diversos locais do mundo, entre eles, Síria, Venezuela, África Subsaariana, Iraque, além de outros, infelizmente.

Assim, o número de pessoas em tal situação cresce sempre mais e chegou a 25,4 milhões, segundo dados da Agência da Organização das Nações Unidas (ONU) para Refugiados (ACNUR), trazendo de volta grande preocupação e foco da comunidade internacional. Levando em conta este contexto, o presente trabalho tem como objetivo analisar a efetivação do acesso dos refugiados ao mercado de trabalho brasileiro, no século XXI, a partir da pesquisa da legislação internacional e nacional e nas obras de Hannah Arendt.

O Brasil tem recebido cada vez mais refugiados, os quais veem o país como um território de oportunidades e de busca por melhores condições de vida, incluindo desde o acesso a serviços públicos de saúde e de educação, bem como ao principal meio de melhoria da condição de vida, o ingresso ao mercado de trabalho.

Refugiado, nos termos da legislação pátria, é aquele indivíduo que, devido a fundados temores de perseguição por motivos de raça, religião, nacionalidade, grupo social ou opiniões políticas, encontra-se fora de seu país de nacionalidade, tornando inviável o seu retorno ao país de origem; ou que, não tendo nacionalidade e estando fora do país onde antes teve sua residência habitual, não possa ou não queira regressar a ele, em função das circunstâncias anteriormente descritas. Em suma, devido à grave e à generalizada violação de direitos humanos, é obrigado a deixar ou a não retornar a seu país de nacionalidade para buscar refúgio em outro. Deste modo, evidente a distinção do conceito de refugiado para o de imigrante: este pode ser considerado como a pessoa natural de outro país ou apátrida que trabalha ou reside e se estabelece, temporária ou definitivamente, no Brasil ${ }^{3}$, sem que haja uma grave violação dos direitos humanos no país de origem.

O tema será analisado sob a ótica de normativos internacionais, destacando-se a Convenção Internacional sobre o Estatuto dos Refugiados de 1951 e seu Protocolo de 1967, da ONU, cuja adesão foi manifestada pelo Brasil, além de Convenções da Organização Internacional do Trabalho (OIT) que contenham direitos que alcancem os refugiados. Será verificado, também, se a Lei de n. 13.445, de 24 de maio de 2017 - Lei dos Refugiados - e se

\footnotetext{
${ }^{3}$ Conferir o art. $1^{\circ}$ da Lei n. 13.445/2017 que traz importantes conceitos para compreensão do tema.
} 
o panorama social brasileiro garantem, na prática, os direitos previstos na Legislação Internacional no que se refere ao acesso ao mercado laboral por parte dos refugiados, após análise de dados do Instituto Brasileiro de Geografia e Estatística (IBGE) e do Alto Comissariado das Nações Unidas para Refugiados (ACNUR).

A despeito disso, o certo é que não se pode negar a existência de dificuldades em tal inserção no mercado de trabalho, tanto por questões da grande crise econômica e social interna no Brasil, para além das barreiras linguísticas; como pela ausência de documentos; falta de informação; e estigmatização do grupo em razão de preconceito por setores da sociedade em relação aos estrangeiros. Por tais razões, há um longo e relevante caminho de concretização de valores e princípios, constantes da legislação internacional e da própria Constituição da República Federativa do Brasil de 1988 (CRFB/88), a qual também sofreu inegável influência internacional.

Quanto à metodologia, optou-se pela pesquisa qualitativa, aliada a procedimento de caráter bibliográfico. A pesquisa qualitativa, que tem como meta trabalhar com dados relativos à realidade que não podem ser quantificados, tende a ressaltar “[...] os aspectos holísticos, dinâmicos, e individuais da experiência humana, para apreender a totalidade no contexto daqueles que estão vivenciando o fenômeno" (POLIT; BECKER; HUNGLER, 2004, p. 201). Entre as diversas técnicas utilizadas na pesquisa qualitativa, destaca-se a Análise de Conteúdo, que pode ser considerada como “[...] um conjunto de instrumentos metodológicos cada dia mais aperfeiçoados que se aplicam a discursos diversos" (RICHARDSON, 1999, p. 223).

\section{TRABALHO DO REFUGIADO NO BRASIL}

A fim de melhor compreender o tema, inicialmente, será feita uma análise da importância da inclusão dos refugiados na visão de Hannah Arendt, com enfoque no direito ao emprego, seguida da normatização internacional e nacional. Por fim, realizar-se-á uma verificação acerca da concretização do direito ao emprego para os refugiados, por meio de dados da ACNUR e IBGE.

2.1. A importância da inclusão dos refugiados na visão de Hannah Arendt, com enfoque no direito ao emprego 
A análise das discussões, promovidas por Hannah Arendt, no século passado, tornouse extremamente atual quando o mundo se depara com um novo "boom" migratório. Isso porque, com o atual aumento do número de pessoas que buscam refúgio, ocasionado por graves violações de direitos humanos, ocorridas nos países de origem, retoma-se o receio que aconteça com o grupo de refugiados o mesmo que se verificou nos tempos de Arendt, com novas e graves violações, também, no país de destino.

Considerando que o deslocamento e as relações sociais são intrínsecos à condição de seres sociais, valores como o da identidade e da permanência assumem fundamental importância para o indivíduo. Assim, Hannah Arendt sempre indicou a questão relativa ao pertencimento ao mundo como importantíssima, vez que não se pode escapar da condição de seres naturais e mundanos. Nesse sentido, a pluralidade humana deve conduzir a ação como categoria política para a integração, evitando-se o isolamento do indivíduo, destituindo-o de seu papel político e restringindo suas capacidades humanas. $\mathrm{Na}$ visão da autora: “O isolamento é aquele impasse no qual os homens se veem quando a esfera política de suas vidas, onde agem em conjunto na realização de um interesse comum, é destruída". (ARENDT, 1989, p. 527).

Por sua vez, a solidão, para a autora, destaca-se como algo ainda mais cruel, visto que retiraria o ser humano do próprio mundo: “[...] a solidão baseia-se na experiência de não pertencer ao mundo" (ARENDT, 1989, p. 41). Assim, ela seria ainda mais grave e danosa ao indivíduo que o isolamento. Os refugiados, para Hannah Arendt, configuram-se como, infelizmente, aqueles que sofreram com a solidão (ARENDT, 2016, p. 478):

Perdemos a nossa casa o que significa a familiaridade da vida cotidiana. Perdemos nossa ocupação o que significa a confiança de que tínhamos algum uso nesse mundo. Perdemos a nossa língua o que significa a naturalidade das reações, a simplicidade dos gestos, a expressão impassível dos sentimentos.

Na obra "A Condição Humana", Arendt aponta uma evidente incapacidade do direito, como um todo, para proteger apátridas e refugiados, fazendo-os como desprotegidos da lei ou Outlaw (ARENDT, 2016, p. 490). Nesse sentido, torna-se evidente a necessidade de proteção da dignidade destes grupos, evitando a deliberada exclusão social que, muitas vezes, ocorre mesmo que as proclamações públicas digam, exatamente, o oposto. Já em "Nós, os Refugiados", a mesma autora destaca que os refugiados não têm direitos de cidadania no país 
em que estão. Portanto, “[...] nunca serão cidadãos do país de refúgio” (ARENDT, 2013, p. 314). Segundo Arendt, nunca houve proteção suficiente aos apátridas e refugiados.

As ideias expressas nos livros foram reveladas pela própria Arendt (2013, p. 15) na condição de refugiada judia na $2^{\mathrm{a}}$ Guerra Mundial:

\begin{abstract}
Essas leis sociais por escrever, embora nunca publicamente admitidas, tinham uma grande força na opinião pública. E tal opinião silenciosa e prática eram mais importantes para a nossa vida quotidiana do que todas as proclamações de hospitalidade e boa vontade oficiais. O homem é um animal social, e a vida não é fácil para ele quando as ligações são cortadas.
\end{abstract}

Em convergência com o relato de Hannah Arendt, indica-se que o trabalho de apoio deve ser efetivo, para que não se limite à barreira da mera propaganda e que grupos concedam o apoio necessário para a plena inclusão na sociedade, ultrapassando os limites do preconceito estrutural. Somente assim, garante-se o sentimento de inclusão no grupo social e a promoção dos requisitos mínimos para uma vida digna, derrubando as barreiras do preconceito ou da xenofobia.

Hannah Arendt escancara os males da discriminação, a qual indica como a maior arma social, ao citar que passaportes serviram como fatos de distinção social. Também há reflexões no sentido que "[...] a experiência de não pertencer ao mundo, que é uma das mais radicais e desesperadas experiências que o homem pode ter" (ARENDT, 2004, p. 527) é experimentada em elevado grau por esses grupos. Ressalta a perda da identidade de povos como grave consequência desta, em que se pode matar um homem sem derramar seu sangue; ou se pode fazê-lo perder a confiança em si próprio se a sociedade não o aprovar, e ainda que se paga qualquer preço para ser aceito (ARENDT, 2013, p. 19).

Muitos dos refugiados tornavam-se, também, apátridas, de maneira a repercutir, gravemente, em sua identidade e trazer inegável opressão e privação de direitos fundamentais (ARENDT, 1989, p. 249):

\footnotetext{
$\mathrm{O}$ apátrida, sem direito à residência e sem o direito de trabalhar, tinha, naturalmente, de viver em constante transgressão à lei. Estava sujeito a ir para a cadeia sem jamais cometer um crime. Mais do que isso, toda a hierarquia de valores existente nos países civilizados era invertida no seu caso. Uma vez que ele constituía a anomalia não prevista na lei geral, era melhor que se convertesse na anomalia que ela previa: o criminoso
}

Nesse sentido, a complexa e multifatorial instalação e a integração dos refugiados na comunidade local perpassam, inexoravelmente, pelo acesso destes a uma atividade remunerada, de forma que possam criar vínculos sociais, bem como prover a sua própria subsistência e as suas necessidades básicas, assim como as de sua família. 
Exsurge, então, a necessidade de não se tratar o refugiado como potencialmente indigno ou como cidadão de segunda classe. Inclusive, a autora indica que o grupo sequer gostava do termo 'refugiados', preferindo recém-chegados ou imigrantes, devido à estigmatização. (ARENDT, 2016, p. 477). É evidente que o não acesso ao emprego, além de conduzir à intensificação da exclusão social, com danos psicológicos e sociais, leva a uma grave transgressão à própria identidade do refugiado. Dessa forma, reforçada a necessidade de se proteger tais grupos por normativas - mas não somente por estas -, assim como por iniciativas e por políticas públicas efetivas na criação de oportunidades de trabalho, evitandose que o erro histórico e a grave omissão do direito, narrada por Hannah Arendt, em seus diversos ensaios, se repita.

\subsection{Normatização internacional acerca do direito ao emprego por parte dos refugiados}

Inicialmente, pertinente expor o panorama da temática do direito ao emprego por parte dos refugiados. Nesse sentido, a Convenção Internacional sobre o Estatuto dos Refugiados da ONU, de 1951, fora criada com o intuito de resolver a situação deste grupo logo ao término da $2^{a}$ Guerra Mundial. Confeccionado para proteger o grupo até 31 de dezembro de 1950, o protocolo de 1967 excluiu essa limitação temporal antes existente. Assim, é permitida a ampla aplicação dos direitos e deveres, previstos no importante instrumento internacional, para que os refugiados não fiquem desamparados, tal como o que ocorria anteriormente. Este mesmo documento indica a legitimidade e a incumbência do AltoComissariado das Nações Unidas para os Refugiados - ACNUR - para verificar e instrumentalizar os direitos ali previstos, prevendo a automática cooperação de cada Estado quando da sua assinatura.

Embora seja louvável o intuito da legislação e o trabalho do ACNUR, o texto escancara a possibilidade de discriminação destes trabalhadores em relação aos nacionais ou de legitimar restrições àqueles estrangeiros, sob determinadas circunstâncias, conforme o artigo 17 da Convenção:

\section{Capítulo III}

EMPREGOS REMUNERADOS

Art. 17 - Profissões assalariadas

1. Os Estados Contratantes darão a todo refugiado que resida regularmente no seu território o tratamento mais favorável dado, nas mesmas circunstâncias, aos nacionais de um país estrangeiro no que concerne ao exercício de uma atividade profissional assalariada. 
2. Em qualquer caso, as medidas restritivas impostas aos estrangeiros ou ao emprego de estrangeiros para a proteção do mercado nacional do trabalho não serão aplicáveis aos refugiados que já estavam dispensados na data da entrada em vigor desta Convenção pelo Estado Contratante interessado, ou que preencham uma das seguintes condições:

a) Contar três anos da residência no país;

b) Ter por cônjuge uma pessoa que possua a nacionalidade do país de residência. Um refugiado não poderá invocar o benefício desta disposição no caso de haver abandonado o cônjuge;

c) Ter um ou vários filhos que possuam a nacionalidade do país de residência.

3. Os Estados Contratantes considerarão com benevolência a adoção de medidas tendentes a assimilar os direitos de todos os refugiados no que concerne ao exercício das profissões assalariadas aos dos seus nacionais, e em particular para os refugiados que entraram no seu território em virtude de um programa de recrutamento de mãode-obra ou de um plano de imigração.

Se, por um lado, exige-se que o refugiado esteja regular no país de destino, por outro, há a evidente possibilidade de se limitar o direito de acesso ao emprego, sob a justificativa de proteção do mercado nacional de trabalho. Tal disciplina normativa também se aplica às profissões liberais, como preconiza o artigo 19 da norma em questão. Há, assim, limitações, havendo exigência da regularização da situação do estrangeiro refugiado, a fim de que este possa exercer suas atividades laborais.

A promulgação da Convenção em tela pelo Brasil deu-se, inicialmente, em 28 de janeiro de 1961, por meio do Decreto de n. 50.125, com a exclusão dos artigos 15 e 17 (este, que trata sobre os empregos remunerados e que foi acima indicado), talvez deixando-os ainda mais desamparados naquele momento. Isso porque a reserva parecia indicar que aos refugiados não caberiam tais direitos.

Posteriormente, foi retirada tal menção, por meio do Decreto n. 99.757, de 29 de novembro de 1990, aduzindo que o Protocolo de 1967, promulgado pelo Decreto n. 70.946, de 7 de agosto de 1972, já não havia feito qualquer limitação aos artigos 15 e 17 da Convenção de 1951. Por outro lado, em relação às normativas da OIT, destaca-se a Convenção de n. 111, de 1958, ratificada pelo Brasil, e que pró́be a Discriminação em Matéria de Emprego e Ocupação. A convenção foi aqui promulgada por meio do Decreto n. 62.150, de 19 de janeiro de 1968, evocando em relação ao tema:

Art. 1 - 1. Para os fins da presente convenção o termo "discriminação" compreende:

a) toda distinção, exclusão ou preferência fundada na raça, cor, sexo, religião, opinião política, ascendência nacional ou origem social, que tenha por efeito destruir ou alterar a igualdade de oportunidade ou de tratamento em matéria de emprego ou profissão;

b) qualquer outra distinção, exclusão ou preferência que tenha por efeito destruir ou alterar a igualdade de oportunidades ou tratamento em matéria de emprego ou profissão que poderá ser especificada pelo Membro interessado depois de 
consultadas as organizações representativas de empregadores e trabalhadores, quando estas existam, e outros organismos adequados.

Assim, a eliminação da discriminação em matéria de emprego e ocupação deve-se operar em relação a todos os trabalhadores migrantes, independentemente de sua situação migratória.

Não obstante tal situação, também no período pós-guerra, a OIT trouxe convenções dedicadas, especificamente, aos trabalhadores migrantes, de forma geral, como a Convenção de número 97, que tem como tema Trabalhadores Migrantes, de 1949, cuja promulgação pelo Brasil ocorreu somente em 1966.

Importante ressaltar, inclusive, o Anexo II, artigo 11 da Convenção n. 97 da OIT, que traz a expressa ideia de que, além de exigir conformidade com a legislação - ou um status "regular" -, os refugiados podem colocar em risco o acesso dos trabalhadores nacionais ao mercado de trabalho, consoante os exatos termos da legislação internacional referida:

Art. 11 - Se um trabalhador migrante que possuir a qualidade de refugiado ou de pessoa deslocada estiver em excesso em um emprego qualquer, em território de imigração onde haja entrado em conformidade com o art. 3 do presente anexo, a autoridade competente deste território deverá fazer todo o possível para permitir-lhe a obtenção de um emprego conveniente que não prejudique os trabalhadores nacionais, e deverá adotar disposições que garantam sua manutenção, enquanto aguarda colocação em emprego conveniente ou a sua fixação noutro local.

Neste contexto, a paridade de direitos empregatícios de tal Convenção, destinada exclusivamente aos trabalhadores migrantes, fora bastante limitada. Embora sua aplicação, com base no artigo 11, é voltada apenas para: (a) trabalhadores fronteiriços; (b) à entrada, por curto período, de pessoas que exerçam profissão liberal e artistas; e (c) aos marítimos. Todavia, o próprio Escritório da OIT no Brasil, por meio do seu informativo sobre Migração Laboral no Brasil (OIT, 2016, p. 23), esclarece que a escrita se deu de forma equivocada e que, na realidade, estas seriam exceções à aplicação - ou seja, não se utilizaria para este grupo. Entretanto, também, notam-se, um tanto quanto limitadas, suas próprias disposições do ponto de vista de conferir direitos de modo efetivo.

Já a Convenção n. 143 da OIT, de 1975, sobre as Imigrações Efetuadas em Condições Abusivas e sobre a Promoção da Igualdade de Oportunidades e de Tratamento dos Trabalhadores Migrantes, visa a coibir o tráfico ilícito ou clandestino de mão de obra, além de 
exigir medidas contra abusos aos trabalhadores migrantes. Apesar da importância da norma, ela não fora ratificada pelo Brasil ${ }^{4}$.

A parte II da Convenção citada acima, não referendada pelo país, destaca sua relevância na busca da concretização da igualdade e da oportunidade de tratamento, previstas na Convenção de n. 87 da OIT. Embora a questão social contida na Convenção seja louvável, não houve sua promulgação no plano interno, acabando por permitir, por omissão, inúmeras violações dos Direitos Humanos destes trabalhadores, além de demonstrar uma atuação estatal não proativa em defesa dos Direitos Humanos dos Refugiados e Imigrantes. Igualmente, não foi ratificada a Convenção da ONU para Proteção dos Trabalhadores Migrantes e seus Familiares, de 1990, a qual entrou em vigor em $1^{\circ}$ de junho de 2003. Embora a sua confirmação tenha sido um compromisso político assumido pelo país em 1996 - conforme divulgado no Plano Nacional de Direitos Humanos - permanece o Brasil como o único país do Mercosul que não ratificou a Convenção em foco.

Além disso, em termos mundiais, entre as nações que não a confirmaram - pois apenas o fora por 41 países, incluem-se as que mais são destino de fluxo migratórios, dando claro sinal negativo em relação à proatividade estatal brasileira na proteção da não discriminação e à questionável tendência de ignorar a promoção dos Direitos Humanos, insculpidos em normativos internacionais.

A Convenção da ONU para Proteção dos Trabalhadores Migrantes e seus Familiares promove, desse modo, a universalização dos direitos dos trabalhadores, expandindo a aplicação das normativas da OIT, além de atualizá-las e com enfoques pormenorizados no tocante à situação de cada migrante, enfatizando os direitos, independentemente do status migratório de regularidade ou não. Abandona-se a ótica de proteção dos trabalhadores ou dos interesses nacionais como se os migrantes ou refugiados estivessem indo para o país para "roubar empregos", ou impõem-se, de forma genérica, óbices ao pleno acesso e à total integração por narrativas, tais como a garantia da ordem pública ou de segurança nacional.

Infelizmente, sem a ratificação de importantes instrumentos internacionais e de promoção dos direitos dos refugiados, de forma efetiva, no Plano Internacional, é cada vez mais possível que se presencie uma dupla violação dos direitos humanos, sendo a primeira no país de origem e, a segunda, no próprio país de destino, o que contradiz a atual ideia de

\footnotetext{
${ }^{4}$ O Decreto Legislativo $\mathrm{n}^{\circ}$ 86, de 14 de dezembro de 1989, aprova os textos das Convenções $n^{\circ}$ s. 135 e 161 e rejeita a de $n^{\circ} 143$ da Organização Internacional do Trabalho.
} 
universalismo dos direitos humanos e o compromisso assumido pelo Brasil em diversas ocasiões.

\title{
2.3. Normatização do tema no âmbito nacional
}

Perpassada a breve análise sobre a legislação internacional, importante verificar a nacional acerca do tema, especialmente por conta das recentes disposições da Lei n. 13.445, de 24 de maio de 2017, a Lei de Migração. Não obstante, tem-se, também, a Lei n. 9.474, de 22 de julho de 1997, que trata especificamente dos refugiados. Esta merece relevante destaque por ser específica ao grupo, cuja análise será feita sempre com enfoque no acesso ao mercado de trabalho.

Além do direito à Cédula de Identidade e à Carteira de Trabalho e Previdência Social, o refugiado tem direito, nos termos da Lei n. 9.494/1997, à obtenção de refúgio e aos demais direitos correlatos, tomando-se como base o Estatuto dos Refugiados de 1951:

\begin{abstract}
Art. $\mathbf{5}^{\circ} \mathrm{O}$ refugiado gozará de direitos e estará sujeito aos deveres dos estrangeiros no Brasil, ao disposto nesta Lei, na Convenção sobre o Estatuto dos Refugiados de 1951 e no Protocolo sobre o Estatuto dos Refugiados de 1967, cabendo-lhe a obrigação de acatar as leis, regulamentos e providências destinados à manutenção da ordem pública.
\end{abstract}

Quanto à integração local, a lei citada acima dispôs, de modo tímido, sobre a facilitação da obtenção de diploma por conta de suas condições desfavoráveis, não sendo, certamente, suficiente à integração plena dos refugiados. Já a Lei n. 13.445/2017 tem as seguintes disposições aplicáveis ao trabalho do Refugiado:

Art. $3^{\mathbf{0}}$ A política migratória brasileira rege-se pelos seguintes princípios e diretrizes:

XI - acesso igualitário e livre do migrante a serviços, programas e benefícios sociais, bens públicos, educação, assistência jurídica integral pública, trabalho, moradia, serviço bancário e seguridade social;

$\mathbf{X V}$ - cooperação internacional com Estados de origem, de trânsito e de destino de movimentos migratórios, a fim de garantir efetiva proteção aos direitos humanos do migrante;

XXI - promoção do reconhecimento acadêmico e do exercício profissional no Brasil, nos termos da lei;

Art. 77. As políticas públicas para os emigrantes observarão os seguintes princípios e diretrizes:

$[\ldots]$

II - promoção de condições de vida digna, por meio, entre outros, da facilitação do registro consular e da prestação de serviços consulares relativos às áreas de educação, saúde, trabalho, previdência social e cultura; 
Evidente que o objetivo da norma citada é, desse modo, facilitar a inserção do indivíduo na sociedade brasileira. Coerente com essa linha de pensamento, rememora-se a chamada constitucionalização do direito, de acordo com a qual todo o direito deve obter compatibilidade e ser lido à luz da Constituição. Com o Direito do Trabalho, não deve ser diferente!

Com efeito, da gama de princípios e regras constitucionais, é possível identificaremse, no texto da CRFB/88, princípios e regras nucleares plenamente aplicáveis ao Direito do Trabalho, tais como a dignidade da pessoa humana, o valor social do trabalho e a função social da propriedade (artigos $1^{\circ}$, III e IV; $5^{\circ}$, XXII e XXII; 170, “caput” e III). Insta destacar que a dignidade da pessoa humana é o valor jurídico de maior hierarquia axiológica do ordenamento jurídico, objetivando promover a solidariedade e a distribuição da justiça na relação entre os seres humanos.

Se não bastasse, é relevante lembrar que se encontram, entre os objetivos da República Federativa do Brasil, a construção de uma sociedade livre, justa e solidária e a promoção do bem de todos, sem preconceitos de origem, raça, sexo, cor, idade e quaisquer outras formas de discriminação. Destaca-se: o Brasil deve pautar a sua atuação, na esfera nacional e internacional, pela prevalência dos direitos humanos, o que, sem dúvida, apenas é possível mediante a tutela dos que se encontram em situação de vulnerabilidade, entre eles, o refugiado.

Deve-se conferir densidade, por outro lado, ao princípio da igualdade, impedindo o tratamento discriminatório, logo, diferenciado, em razão de um critério injustamente (des)qualificante. Ressalta-se, uma vez mais, que todos são iguais perante a lei, sem distinção de qualquer natureza, garantindo-se aos brasileiros e aos estrangeiros os direitos fundamentais, sendo possível o reconhecimento de restrições aos direitos dos estrangeiros, tão somente em caso de expressa previsão constitucional ou se a natureza do direito for incompatível com eventual transitoriedade no território nacional.

Especificamente, quanto às relações de trabalho, o texto constitucional deixa evidente a incidência do princípio da igualdade, vedando diferença de salários, de exercício de funções e de critério de admissão por motivo de sexo, idade, cor ou estado civil, bem assim prevendo a proibição de distinção entre trabalho manual, técnico e intelectual ou entre os profissionais respectivos. Deste modo, devem ser reconhecidos aos refugiados todos os direitos compatíveis com a natureza da relação jurídica de trabalho e, em sendo uma relação 
de emprego, todos os direitos inerentes à condição de empregado, sem discriminação de qualquer tipo.

Por consequência, o tratamento diferenciado e restritivo quanto à pessoa do refugiado, inclusive no que diz respeito ao acesso ao mercado de trabalho, viola direitos e garantias fundamentais, expressamente consagrados no ordenamento jurídico, devendo o Estado e a sociedade atuarem em conjunto em busca da promoção de todos, sem qualquer espécie de discriminação.

Quanto ao tema, é relevante apontar a íntima relação entre o reconhecimento de direitos ao refugiado, em patamares minimamente aceitáveis, e os fundamentos da República Federativa do Brasil, expressamente previstos no texto constitucional, especialmente a dignidade da pessoa humana e o valor social do trabalho e da livre inciativa. É sob tal perspectiva que precisa ser analisada a condição do trabalhador refugiado. Vale dizer: deve ser visto como um tema que busca discutir direitos humanos e direitos fundamentais.

Por outro lado, é pertinente destacar que a CRFB/88 deixa clara a existência de um "catálogo aberto" de diretos e de garantias fundamentais, prevendo expressamente que "os direitos e garantias expressos nesta Constituição não excluem outros decorrentes do regime e dos princípios por ela adotados, ou dos tratados internacionais em que a República Federativa do Brasil seja parte" (art. $5^{\circ}, \S 2^{\circ}$ ), regra complementada pelo $\S 3^{\circ}$, do mesmo artigo $5^{\circ}$, que permite, observado determinado procedimento, que os tratados internacionais sejam incorporados com status de emenda constitucional.

Sabe-se que a noção de "bloco de constitucionalidade", estabelecida pela CRFB/88, é bastante ampla, sendo possível afirmar que o rol de direitos e de garantias, previstos na norma nacional, é meramente exemplificativo, não exaustivo. Isto coincide, inclusive, com o disposto na Constituição da Organização Internacional do Trabalho - OIT (art. 19, $\S 8^{\circ}$ ), segundo a qual, havendo conflito entre a legislação interna de um país e uma norma internacional, deve prevalecer a regra mais favorável ao trabalhador. Deste modo, uma convenção ratificada por determinado país não pode alterar regras nacionais mais favoráveis ao trabalhador. É o que se chama de condição nacional mais favorável à pessoa humana.

\subsection{Verificação acerca da concretização do direito ao emprego para os refugiados, por meio de dados da ACNUR e IBGE}


Com efeito, se por um lado é inquestionável a existência de um arcabouço jurídico favorável - embora talvez não suficiente - ao acolhimento de refugiados no Brasil, o certo é que, por outro, tais pessoas enfrentam uma série de dificuldades no território nacional, desde o acesso a serviços básicos de saúde e de educação até o alcance de uma vaga no mercado de trabalho.

Para se verificar se há uma cortina de exclusão social, indo em direção oposta ao que preconiza a legislação nacional e internacional, é importante a análise dos dados e das informações sobre a empregabilidade dos refugiados no país, bem como a comparação destes com os dados gerais de empregabilidade, de forma que se possa verificar eventual proceder discriminatório ou não inclusivo da comunidade local em relação a esses estrangeiros.

Conforme apontado por Savy (2018), uma das grandes barreiras dos refugiados é o acesso à moradia e ao mercado de trabalho. Por tal motivo, em muitos países da Europa, concede-se um auxílio financeiro aos refugiados. No Brasil, entretanto, não há tal tipo de auxílio, sendo garantido aos refugiados, pela lei, o mesmo direito que aos nacionais. Nessa perspectiva, Savy (2018, p. 195) indica que "Sem políticas habitacionais e com condições de aluguéis que exigem um fiador ou pagamentos antecipados como garantia, muitos refugiados sobrevivem de favores e boas ações de instituições filantrópicas e religiosas".

Na busca pela promoção de políticas favoráveis aos refugiados, a Organização das Nações Unidas criou, em 1950, uma agência, o ACNUR - Alto Comissariado das Nações Unidas para Refugiados -, que atua para proteger os direitos das pessoas em situação de refúgio em todo o mundo. Deve-se destacar que a ACNUR, inclusive, possui escritório no Brasil e tem um importantíssimo papel de integração e de promoção dos direitos desses indivíduos, bem como elabora, ainda, diversos levantamentos de dados que permitem se ter uma melhor compreensão do tema. E, com base nesses dados da ACNUR, avalia-se a concretização dos direitos dos refugiados ao acesso do mercado de trabalho no Brasil.

Assim, em nível mundial, de acordo com o site ${ }^{5}$ da referida Agência da ONU, há, atualmente, cerca de 25,4 milhões de refugiados em todo o mundo, sendo a maior parte deles provenientes da Síria, seguida do Afeganistão. Quanto aos países de destino, destaca-se a Turquia como o que mais recebeu refugiados. No que concerne aos números em relação ao Brasil, mais uma vez consoante o site da referida Agência, tem-se:

\footnotetext{
${ }^{5}$ Disponível em: https://www.acnur.org. Acesso em: 02 jun. 2021
} 
Segundo dados divulgados pelo Comitê Nacional para os Refugiados (CONARE) na $5^{\text {a }}$ edição do relatório "Refúgio em Números", o Brasil reconheceu, apenas em 2019, um total de 21.515 refugiados de diversas nacionalidades. Com isso, o país atinge a marca de 31.966 pessoas reconhecidas como refugiadas pelo Estado brasileiro.

A nacionalidade com maior número de pessoas refugiadas reconhecidas, entre 2011 e 2019, é a venezuelana, seguida dos sírios e congoleses.

O ano de 2019 foi o maior em número de solicitações de reconhecimento de condição de refugiado. Isso porque o fluxo venezuelano de deslocamento aumentou exponencialmente. No total, foram 82.520 solicitações no ano, sendo $65,1 \%$ de venezuelanos. Em segundo lugar está o Haiti, com $20,1 \%$ das solicitações. Na sequência estão os cubanos, com $4,8 \%$ das solicitações.

Em 2019, 81,74\% das solicitações apreciadas pelo Conare foram registradas nas UFs que compõem a Região Norte do Brasil. O estado de Roraima concentrou o maior volume de solicitações de refúgio apreciadas pelo Conare, em 2019, 56,72\%, seguido pela UF Amazonas, 23,38\%.

Tais dados são relevantes ao objetivo do presente artigo, que busca, precisamente, analisar a efetivação do acesso dos refugiados ao mercado de trabalho brasileiro, sendo possível afirmar que é crescente o número de pessoas que buscam refúgio no território nacional; que a maior parte dos refugiados é oriunda da Venezuela, seguida da Síria e do Congo; e que a maioria deles busca a permanência em dois Estados do norte do país, Roraima e Amazonas.

Neste sentido, segundo o R4V Plataforma de Coordinación para Refugiados y Migrantes de Venezuela (em tradução livre, R4V Plataforma de Coordenação para Refugiados e Migrantes da Venezuela), o total de refugiados e migrantes deste país, no Brasil, estava em 261.441 (duzentos e sessenta e um mil, quatrocentos e quarenta e um), conforme site ${ }^{6}$, que indica tal número até 31 de outubro de 2020. A maior parte desses refugiados é assistida pela Operação Acolhida, iniciada em abril de 2018, portanto, bastante recente e formada pela parceria do Governo Federal, com o apoio do ACNUR, outras agências da ONU e com mais de 100 organizações da sociedade civil. Assim, há um esforço para prestar-lhes assistência social adequada e para que sejam emitidos CPF e Carteiras de Trabalho, sendo oferecido abrigo com condições básicas e aulas de português, além de demais, também básicas, de dignidade.

Após, há uma tentativa de "interiorização" voluntária do grupo, pois a maior parte destes chega a Roraima, de forma que há uma necessidade de conduzi-los aos demais locais com melhores perspectivas econômicas. Apenas são realocados os venezuelanos regularizados, imunizados, avaliados clinicamente e com termo de voluntariedade assinado. Este grupo chegou a mais de 27.000, até dezembro de 2019, segundo dados da ACNUR.

\footnotetext{
${ }^{6}$ Disponível em: https://r4v.info/es/situations/platform/location/7509. Acesso em 30 maio 2021.
} 
A maior parte das realocações é agrupada em cinco estados com melhores perspectivas de empregabilidade: São Paulo, Amazonas, Santa Catarina, Rio Grande do Sul e Paraná. Nesse grupo de venezuelanos assistido, os dados são alarmantes: apenas 10\% estavam empregados formalmente. Em comparação, 34\% da população adulta no Brasil trabalha no setor formal. Além disso, para os trabalhadores venezuelanos que não conseguem atingir uma renda acima do teto do bolsa família, ou por precariedade dos trabalhos conquistados, ou por dificuldade no acesso ao mercado de trabalho, há outra informação preocupante: embora a população brasileira e a venezuelana no Brasil tenham proporções semelhantes de famílias pobres e extremamente pobres, $21 \%$ dos brasileiros acessam o Bolsa Família, enquanto apenas $6,5 \%$ dos venezuelanos o fazem.

Quanto ao acesso ao emprego em relação aos refugiados, a ACNUR efetuou um levantamento, entre os dias 13 de junho de 2018 e 20 de fevereiro de 2019, que mostra que se concentravam em oito Unidades Federativas distintas, naquele momento: Rio Grande do Sul, Rio de Janeiro, Santa Catarina, Paraná, São Paulo, Minas Gerais, Amazonas e Distrito Federal.

A partir desse levantamento, fora elaborado um Resumo Executivo para servir de subsídio à elaboração de políticas públicas. Em tal estudo, ficou escancarado o altíssimo nível de desemprego, apesar do amparo por tal entidade, pois apenas 57,5\% destes estavam laborando. A fim de permitir uma melhor visualização da situação indesejada, abordada por este Resumo Executivo, veja-se a seguinte figura:

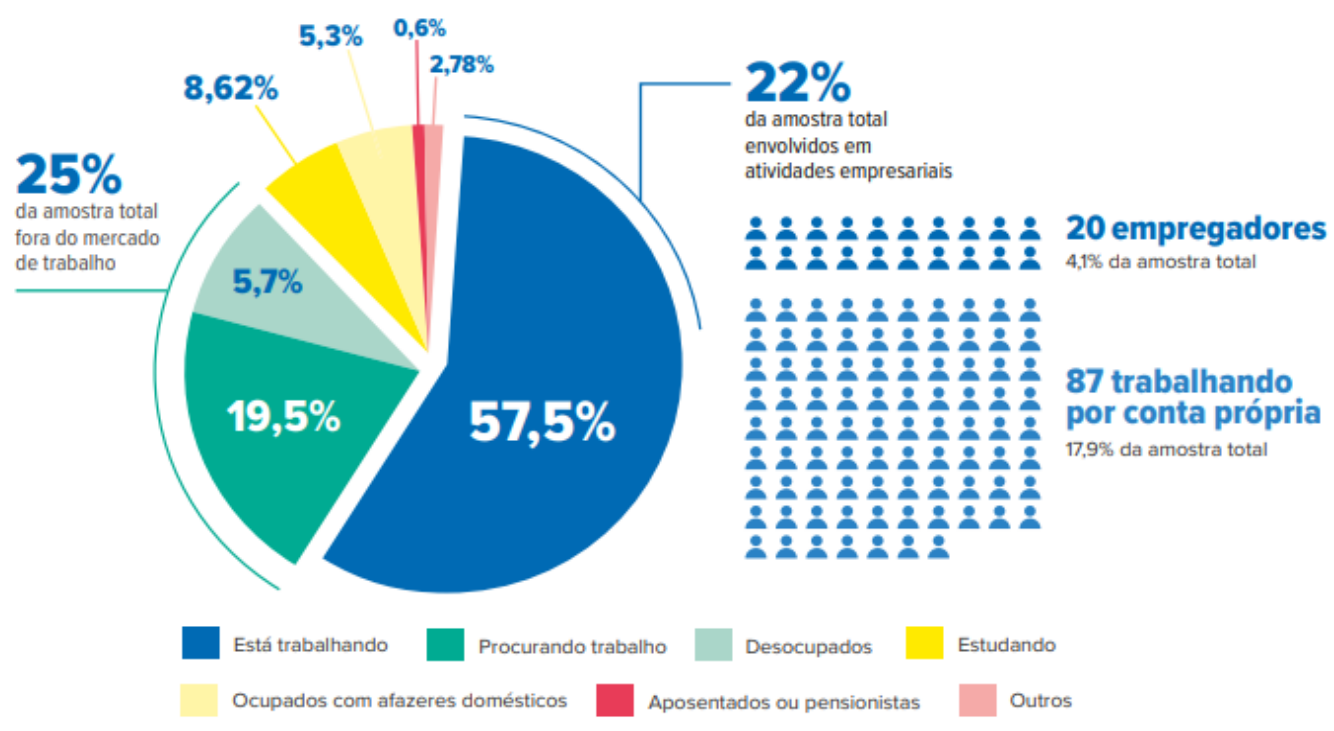


Fonte: Extraída do Resumo Executivo feito pela ACNUR, 2018, p. 08. Disponível em: < Resumo-ExecutivoVersão-Online.pdf (acnur.org) > Acesso em: 25 maio 2021.

Por outro lado, conforme dados do IBGE, a taxa de desocupação da população brasileira, em geral, variou entre $12,4 \%$ e $11,6 \%$, no mesmo período, como indica a seguinte figura:

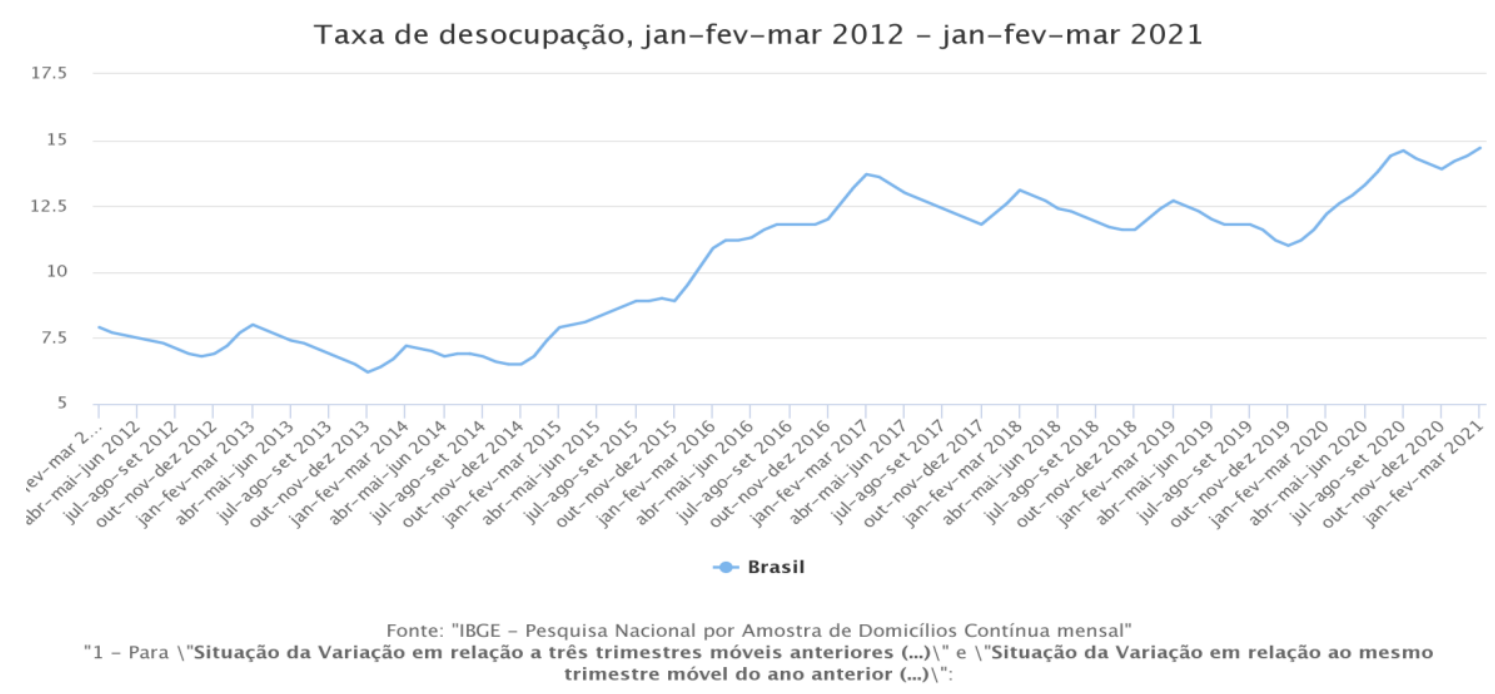

Neste contexto, constata-se que a desocupação entre os refugiados é muito superior à dos trabalhadores brasileiros, em geral. Apesar de o Relatório Executivo indicar que os refugiados possuem elevado capital linguístico e escolar muito acima da média brasileira, boa parte dos refugiados tem ensino médio completo (quase $50 \%$ deles) e 34,4\% já haviam concluído o Ensino Superior.

O próprio estudo ressaltou que, em comparação, segundo a Pesquisa Nacional por Amostra de Domicílios Contínua - PNAD 2017, 33,8\% da população brasileira tem o ensino fundamental incompleto e apenas $26,8 \%$ concluíram o ensino médio completo. E isso teria ocorrido mesmo considerando que os dados educacionais para o Brasil se referem à população adulta, ou seja, com mais de 25 anos, enquanto nosso universo foi composto de pessoais com mais de 18 anos.

Considerando tal disparidade de bases, revela-se um abismo ainda maior em relação à qualificação dos refugiados e dos brasileiros, sendo a dos refugiados, pelo grupo analisado, muito maior, apesar de o desemprego ser muito mais acentuado, mesmo entre aquele grupo mais instruído. Inclusive, entre as barreiras e dificuldades enfrentadas pelo grupo, indica o relatório: 
Nota-se aqui a persistência do fator "ser estrangeiro" como obstáculo - também citado como dificuldade para obtenção de emprego - que também pode ser vinculado ao "problema" com o idioma. Isso comprova a análise geral de uma população recentemente instalada no Brasil, muito ligada à família e aos nacionais, pouco integrada, com pouco conhecimento formal da sociedade brasileira e ainda à procura de seus próprios espaços socioeconômicos. (MELO, 2019, p.10)

Deve-se ressaltar que a colocação dos refugiados no mercado de trabalho, ao menos nos níveis dos nacionais, continua a ser um desafio atual- embora talvez menos intenso, por conta das tentativas de integração destes -, semelhante às dificuldades estruturais já citadas por Hannah Arendt no seu refúgio após a $2^{\text {a }}$ Guerra Mundial.

\section{CONCLUSÃO}

O tema do refúgio é tão antigo quanto a humanidade e continua sendo de absoluta relevância, tendo em vista a multiplicidade de fatores envolvidos na formação dos deslocamentos forçados e a complexa realidade dos refugiados, tanto na origem, quanto no destino. Isso porque vivencia-se uma das mais intensas crises migratórias, impulsionada por conflitos armados, crises humanitárias, políticas e/ou sociais em diversos locais do mundo, entre eles, Síria, Venezuela, África Subsaariana, Iraque, além de outros, infelizmente.

Quanto ao tema, é relevante apontar a íntima relação entre o reconhecimento de direitos ao refugiado, em patamares minimamente aceitáveis, e os fundamentos da República Federativa do Brasil. É evidente que o não acesso ao emprego, além de conduzir à intensificação da exclusão social, com danos psicológicos e sociais, gera uma grave transgressão à própria identidade do refugiado. Devem ser reconhecidos aos refugiados todos os direitos compatíveis com a natureza da relação jurídica de trabalho e, em sendo uma relação de emprego, todos os direitos inerentes à condição de empregado.

A normatização internacional traz, ela própria, a possibilidade de discriminação dos refugiados em relação aos nacionais, sob os pretextos de garantir a ordem pública, a segurança nacional ou da proteção do mercado de trabalho nacional. Assim, evidente a estigmatização que acompanha o grupo. Os instrumentos internacionais, ratificados pelo país, carecem de maior aplicabilidade e abrangência no sentido de se integrar os refugiados. E isso poderia ter sido suprido, parcial ou totalmente, pelos instrumentos que não foram validados pelo Brasil. 
A própria não confirmação, pelo país, de relevantes e garantidores instrumentos de proteção aos refugiados, denota uma omissão em relação ao grupo. Assim, a Convenção 143 da OIT, de 1975, e a Convenção da ONU para Proteção dos Trabalhadores Migrantes e seus Familiares, de 1990, merecem destaque. Quanto à última, especialmente, sua não validação como instrumento normativo do país merece críticas, tanto por ter-se omitido em relação a esse importantíssimo instrumento de integração do grupo, quanto por ter agido em contrariedade as suas próprias promessas ao ter assumido o compromisso de referendá-las no Plano Nacional de Direitos Humanos do país. O fato de ser o único país do Mercosul a assim proceder torna a omissão deliberada ainda mais passível de críticas.

A normatização do tema, em âmbito nacional, em cotejo com a própria Constituição Brasileira, é bastante garantista, apesar de não serem identificadas políticas públicas suficientes a integrar esses grupos e a garantir-lhes o direito ao emprego. Assim, verifica-se, ainda, uma cortina de exclusão social de tais grupos, necessitando de políticas públicas mais incisivas, especialmente no tocante a um trabalho de conscientização do país como nação acolhedora, de modo a evitar eventual sentimento de que os postos de trabalho estariam sendo "tomados" pelos estrangeiros, ao revés de serem considerados como agentes sociais que podem trazer uma intensa troca cultural e crescimento econômico para o próprio país, como força produtiva a somar ao progresso.

A análise das discussões, promovidas por Hannah Arendt, no século passado, tornase extremamente atual quando os continentes se deparam com um novo "boom" migratório. Os refugiados, para Arendt, são aqueles que têm a infelicidade de chegarem ao novo país sem recursos e precisarem da ajuda dos comitês de refugiados, mesmo possuindo cidadania. A ampliação de suas vidas é pela caridade e não, por intermédio do direito.

Assim, salienta-se o necessário maior engajamento do Poder Público e dos demais setores da sociedade para integração local efetiva dessa população. Relevante o trabalho do Governo Federal, da ACNUR, das demais entidades civis de apoio, que passam a ter papel de inegável destaque para coleta de dados que subsidiem políticas públicas, bem como de ação direta em prol de tais grupos, ultrapassando as barreiras do mero assistencialismo em sua chegada, a fim de que haja efetiva proteção e concretização dos direitos humanos.

\section{REFERÊNCIAS}


ARENDT, Hannah. A condição humana. Tradução de Roberto Raposo. Rio de Janeiro: Forense Universitária, 2016.

Nós, os refugiados. Tradução de Ricardo Santos, Covilhã: LusoSofiapress, 2013. Disponível em: http://www.lusosofia.net/textos/20131214hannah_arendt_nos_os_refugiados.pdf. Acesso em 09 jul.2021.

Homens em tempos sombrios. Tradução de Denise Bottmann. São Paulo: Companhia das Letras, 2004.

Origens do totalitarismo. Tradução de Roberto Raposo. São Paulo: Companhia das Letras, 1989.

BARBOSA, Bia. Brasil é único do Mercosul a não assinar convenção da ONU. Agência Carta Maior. 2006. Disponível em: < https://reporterbrasil.org.br/2006/12/brasil-e-unico-domercosul-a-nao-assinar-convencao-da-onu/> Acesso em: 10 maio 2021.

BRASIL. [Constituição (1988)]. Constituição da República Federativa do Brasil. Brasília, DF, Senado Federal, 2016. Disponível em: < https://www2.senado.leg.br/bdsf/bitstream/handle/ id/518231/CF88_Livro_EC91_2016.pdf. > Acesso em: 29 maio 2021.

BRASIL. Decreto no. 58.819, de 14 de julho de 1966. Promulga a convenção no 97 sobre os Trabalhadores Migrantes. Diário Oficial da União: seção 1, Brasília, DF, página 8001, 19 de jul. de 1966.

BRASIL. Decreto n. 62.150, de 19 de janeiro de 1968. Promulga a Convenção no 111 da OIT sobre a discriminação em matéria de emprego e profissão. Diário Oficial da União: seção 1, Brasília, DF, página 745, 23 de jan. de 1969.

BRASIL. Decreto no 70.946, de 7 de agosto de 1972. Promulga o Protocolo sobre o Estatuto dos Refugiados. Diário Oficial da União: seção 1, Brasília, DF, página 7037, 8 de ago. de 1972.

BRASIL. Decreto $\mathrm{n}^{\circ}$ 99.757, de 29 de novembro de 1990. Retifica o Decreto $\mathrm{n}^{\circ} 98.602$, de 19 de dezembro de 1989, que deu nova redação ao Decreto de $n^{\circ} 50.125$, de 28 de janeiro de 1961. Convenção relativa ao Estatuto dos Refugiados. Diário Oficial da União: seção 1, Brasília, DF, página 23223, 4 dez.1990.

BRASIL. Lei $n^{\circ}$ 9.474, de 22 de julho de 1997.Define mecanismos para a implantação do Estatuto dos Refugiados de 1951, e determina outras providências. Diário Oficial da União: seção 1, Brasília, DF, página 15822, 23 de jul. 1997.

BRASIL. Lei no 13.445, de 24 de maio de 2017. Institui a Lei de Migração. Diário Oficial da União: seção 1, Brasília, DF, página 1, 25 de maio de 2017.

CONVENÇÃO RELATIVA AO ESTATUTO DOS REFUGIADOS (1951). Alto Comissariado das Nações Unidas para os Refugiados (ACNUR). Disponível em: < 
https://www.acnur.org/fileadmin/Documentos/portugues/BDL/Convencao_relativa_ao_Estatu to_dos_Refugiados.pdf. > Acesso em: 29 maio 2021.

DALLARI, P. A. B. A recepção do tratado internacional no Direito Brasileiro: uma proposta de sistema integrador. Tese de doutorado apresentada ao Departamento de Direito Internacional da Faculdade de Direito do Largo de São Francisco da Universidade de São Paulo, 1999.

Discriminação em Matéria de Emprego e Ocupação. C111 - Organização Internacional do Trabalho (OIT). Brasília. 2016. Disponível em: < https://www.ilo.org/brasilia/convencoes/WCMS_235325/lang--pt/index.htm> Acesso em: 25 maio 2021.

IBGE - Instituto Brasileiro de Geografia e Estatística, 1998. Pesquisa Nacional por Amostra de Domicílios - 1997. Rio de Janeiro: IBGE. Disponível em: < https://www.ibge.gov.br/estatisticas/sociais/trabalho/9173-pesquisa-nacional-por-amostra-dedomicilios-continua-trimestral.html? $=\& \mathrm{t}=$ series-

historicas\&utm_source=landing\&utm_medium=explica\&utm_campaign=desemprego > Acesso em: 30 maio 2021.

MELO, Sergio Vieira de. Perfil Socioeconômico dos Refugiados no Brasil. Agência da ONU para Refugiados. Disponível em: < https://www.acnur.org/portugues/wpcontent/uploads/2019/05/Resumo-Executivo-Versa\%CC\%83o-Online.pdf> Acesso em: 25 maio 2021.

POLIT, D. F.; BECK, C. T.; HUNGLER, B. P. Fundamentos de pesquisa em enfermagem: métodos, avaliação e utilização. Trad. de Ana Thorell. 5. ed. Porto Alegre: Artmed, 2004.

RICHARDSON, R. J. Pesquisa social: métodos e técnica. São Paulo: Atlas, 1999.

SAVY, Renato Ferraz Sampaio. A Inclusão social dos refugiados e imigrantes no Brasil. Rev. do Trib. Reg. Trab. 10 ${ }^{\mathbf{a}}$ Região, Brasília, v. 22, n. 1, 2018.

Venezuelanos no Brasil: Integração No Mercado de Trabalho e Acesso a Redes de Proteção Social. La agencia de La ONU para Los Refugiados. Disponível em: <https://www.acnur.org/portugues/wp-content/uploads/2020/07/Estudo-sobreIntegra\%C3\% A7\% C3\% A3o-de-Refugiados-e-Migrantes-da-Venezuela-no-Brasil.pdf. Acesso em: 30 maio 2021. 